\title{
The Finite Element Analysis of the Stress Field in the Core of Continuous Casting Slab
}

\author{
Qiang Yin \\ College of Mechanical Engineering \\ Polytechnic University \\ Wuhan, China \\ e-mail: ydqking1210@xyz.com
}

\author{
Gongfa Li \\ College of Machinery and Automation \\ Wuhan University of Science and Technology \\ Wuhan, China \\ e-mail: ligongfa@yahoo.com.cn
}

\begin{abstract}
The continuous caseter was widely used of in steelmaking enterprises, with the improvement of product quality, the optimization of the cost control and the improvement of production efficiency, the process requirements in production the was continuously improved and updated. The velocity of cooling water was taken as a variable to conduct the numerical simulation analyze of the entire model. $6 \mathrm{~m} / \mathrm{s}, 8 \mathrm{~m} / \mathrm{s}, 10 \mathrm{~m} / \mathrm{s}, 12 \mathrm{~m} / \mathrm{s}, 14 \mathrm{~m} / \mathrm{s}$ were set as velocity of cooling water respectively, and then used the finite element method to analysis the stress of the core of the slab. In the stress field analysis, when the cooling water speed was up to $10 \mathrm{~m} / \mathrm{s}$, the decline of billet stress was the most notable, which decreased 50MPa. When the velocity water was other value, the stress decreased as well, but the decreased was slight. So that set the crystallizer cold water speed as $10 \mathrm{~m} / \mathrm{s}$ was the optimal decision, which effectively supported the continuous casting production with theory.
\end{abstract}

Keywords-the finite element analysis;Stress field;Core of slab;Continuous caster;Steelmaking

\section{INTRODUCTION}

During the production process, some steelmaking enterprises was facing the over high temperature of continuous casting slab in the arc slab continuous caster[13], which resulted in difficulties the subsequent process of the production[4,5]. In order to ensure the product with high quality and good value, firstly, the temperature field $[1,2]$ and stress field were taken into consideration to find out the cause of quality restrictive process[6,7]. And then, an in-deep and comprehensive study should be conducted to help understanding different phenomena and the complex essence of the continuous casting process. Finally, the existing cooling system was evaluated according to the temperature and stress distribution of the slab, which contributed to the parameters optimization of production process. This study helped to ensure the best quality of the casting billet in continuous casting process and served continuous casting manufacturing.

\section{FINITE ELEMENT MESH GENERAITON OF SLAB}

The dimensions of the wide face of copper crystallizer were $1980 \times 900 \times 45$ (length $X$ width $X$ height), the dimensions of narrow face were $221 \times 900 \times 45$ (length $X$ width $\mathrm{X}$ high), the size of casting billet model was set according to inner dimension of the copper cavity[8].
Firstly, the sketch should be drawn according to the specific size. Then, according to the characteristics of its shape of different parts, by stretching, rotating or removing command to generate the solid parts by using 3D modeling application for modeling design. Finally, the 3D model of billet was shown in Fig .1.

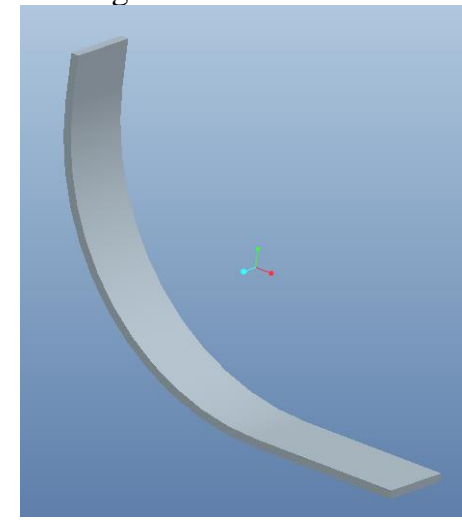

Figure 1. The 3D model of billet

After creating the 3D model, the mesh should be generated with the cell size of 50, which was the modeling relative size. Since the models were built in millimeter, the overall size was large, to reduce the amount of calculation and to keep a certain accuracy as well, the unit size was set to 50. The grid is completed with 75404 nodes and 59820 units, as shown in Fig .2. all of the units were hexahedral.

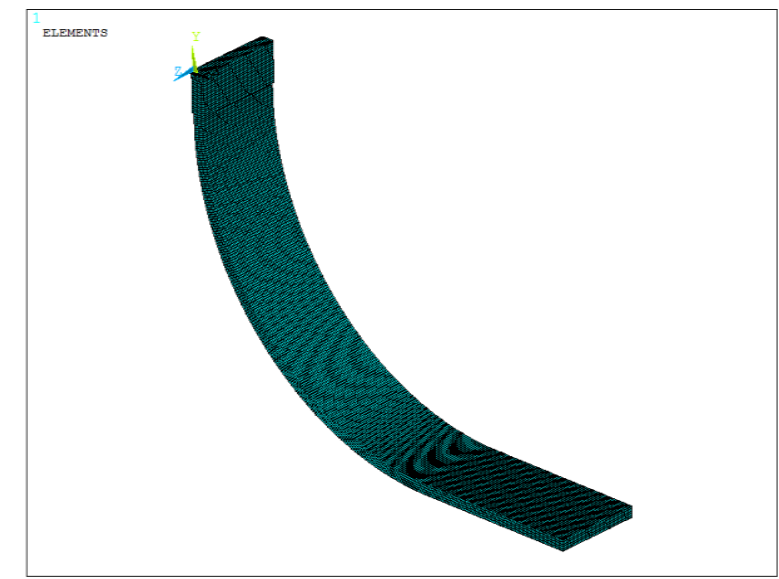

Figure 2. The meshing of billet 


\section{THE STRESS FIELD OF BILLET}

\section{A. The mechanical parameters of billet in continuous casting process}

In the process of molten steel transforming from liquid to solid state and generating the billet, those parameters of its performance were continuously variable[9], such as elastic modulus, tensile strength, plastic hardening, shrinkage coefficient, Poisson's ratio, etc., and the billet critical strain and stress values in different temperatures and deformation conditions.

\section{1) The elastic modulus}

Under the high temperature, in the process of the molten steel gradually solidified, the elastic modulus of different states were also variable, while the temperature and chemical compositions were altered. Rigid was used to represent how easily the elastic deformation of metal materials. The deformation in the elastic limit range, refers to the elastic modulus of materials. The expression of the following (1) was the relationship between stress and strain at the elastic deformation stage, the ratio was the elastic modulus.

$$
E=\frac{\sigma}{\varepsilon}
$$

During the elastic deformation process, E could be determined by the ratio of stress to strain which corresponding to the elastic limit[10], and it was linear. But in the non-elastic region, or in the physical form changing circumstances, the elastic modulus was not easy to be determined by the ratio of the stress and strain, which needed to determine the effect of billet on its elastic modulus when the billet shape changing with temperature changes, as well as the yield stress which corresponding to the temperature and strain rate. It was a more complex relationship, but through the continuous efforts of their predecessors, and now the relationship between the elastic modulus of carbon steel and temperature through continuous efforts of predecessors, the relationship between carbon steel of the elastic modulus with temperature as shown in (2):

$$
E\left(N / \mathrm{cm}^{2}\right)= \begin{cases}1.96 \times 10^{6}-1837.5(T-1000), & 1000^{\circ} \mathrm{C} \leq T \leq 1400^{\circ} \mathrm{C} \\ 1.225 \times 10^{6}(1475-T) / 75, & 1400^{\circ} \mathrm{C} \leq T \leq 1475^{\circ} \mathrm{C} \\ 0 & T \geq 1475^{\circ} \mathrm{C}\end{cases}
$$

\section{2) The expansion coefficient}

The stress which the billet was subjected in the crystallizer was mainly from two different aspects, one aspect was due to its uneven temperature distribution of billet, each part of the material mutual extrusion, resulting in thermal stress, on the other hand, in the process of crystallizer oscillation, the outer surface of the billet was subjected the mechanical force of the crystallizer inner wall. Usually the linear expansion coefficient was used to express the degree of deformation. In the simulation of this study, a portion of the measured data of the linear expansion coefficient was used to simulate and calculate.
The effective thermal expansion coefficient could be calculated by (3),

$$
\alpha=\frac{\left(V / V_{\mathrm{ref}}\right)^{1 / 3}-1}{T-T_{\text {ref }}}
$$

The type: $\mathrm{V}$ - the volume of temperature $\mathrm{T}$; $\mathrm{V}_{\text {ref }}$ - materials volume in benchmark reference temperature $T_{\text {ref }}$.

3) Tensile strength

The slab of continuous casting at different temperatures without cracks on its surface, the allowed maximum intensity was called the slab of high temperature fracture strength. The strength index based on the analysis of the strength of the metal material of high temperature working conditions limit was very important, it was also a very important indicator in this article to study the stress state of continuous casting, the standard could be used to measure whether the slab surface was the main criterion of crack. According to the experimental test the relationship between the tensile strength and temperature as shown in Table I , and themechanical properties of slab are shown in Table II .

TABLE I. TABLE TYPE STYLESTHE RELATIONSHIP BETWEEN THE TENSILE STRENGTH AND TEMPERATURE

\begin{tabular}{|l|c|c|c|c|c|c|c|c|}
\hline $\begin{array}{c}\text { Temperature } \\
\left({ }^{\circ} \mathrm{C}\right)\end{array}$ & 850 & 900 & 950 & 1000 & 1050 & 1100 & 1250 & 1300 \\
\hline $\begin{array}{l}\text { maximum } \\
\text { stress }(\mathrm{MPa})\end{array}$ & 85.34 & 81.2 & 70.21 & 48.96 & 40.56 & 34.81 & 17.81 & 15.02 \\
\hline
\end{tabular}

TABLE II. MECHANICAL PROPERTY PARAMETERS OF SLAB

\begin{tabular}{|l|c|c|c|c|c|}
\hline Temperature $\left({ }^{\circ} \mathrm{C}\right)$ & 25 & 100 & 200 & 300 & 400 \\
\hline $\begin{array}{l}\text { Elastic Modulus } \\
(\mathrm{GPa})\end{array}$ & 117 & 117 & 117 & 117 & 117 \\
\hline Poisson's ratio & 0.36 & 0.36 & 0.36 & 0.36 & 0.36 \\
\hline $\begin{array}{l}\text { Thermal expansion } \\
\text { coefficient }\left(\mathrm{K}^{-1}\right)\end{array}$ & $1.65 \times 10^{-5}$ & $1.67 \times 10^{-5}$ & $1.69 \times 10^{-5}$ & $1.75 \times 10^{-5}$ & $1.79 \times 10^{-5}$ \\
\hline Yield stress (MPa) & 187.38 & 183.49 & 166.69 & 141.17 & 119.4 \\
\hline
\end{tabular}

In the actual casting process, generally speaking, the slab of the compressive strength was greater than the tensile strength, and at least more than 4 times, so we could generally ignore slab' s stress .But when slab was under a certain temperature, the structure of the point in the stress value was more than the allowed ,the slab crack would happen.

\section{B. Slab stress field under different cooling speed}

Transform finite element unit by thermal analysis unit SOLID70 unit SOLID185 for structure analysis, it was often used in the thermal analysis of indirect analysis method, the first analysis of the temperature field of structure, then the results as the load of structure analysis of temperature field all loaded into the finite element model, and the finite element of change constraints, to meet the boundary conditions of structure analysis, the results of analysis was caused by the influence of temperature on the structure .The method could be operated more flexibly in thermal analysis, and could 
separate the temperature and stress results, and ensure the relevance. We would respectively thought the temperature field under different cooling rate as the load of the structure of the load on the finite element mesh, and applying constraints according to the actual working condition, to ensure that the structure boundary conditions were acceptable, then analyzed numerical simulation, the results of the analysis was shown in Fig .3.

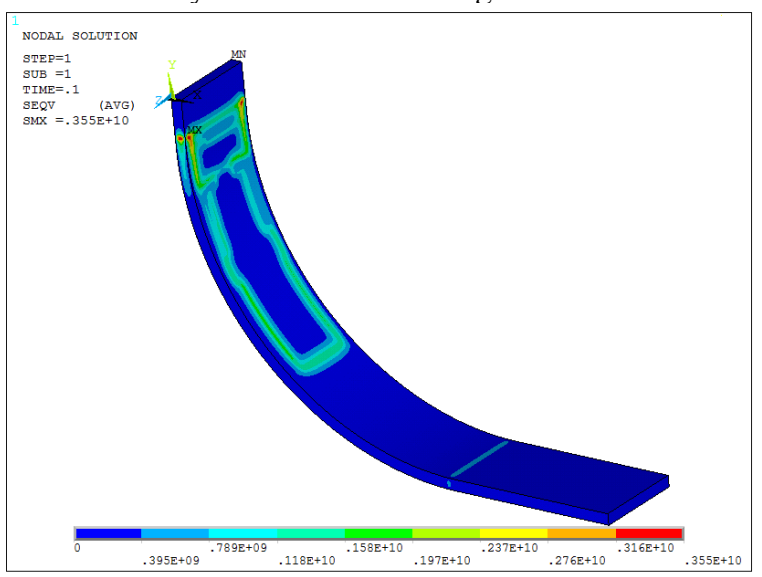

Figure 3. Casting billet stress distribution nephogram when cooling water speed is $6 \mathrm{~m} / \mathrm{s}$

The selected node in different cooling water velocity temperature values plotted curves combined with a coordinate chart, observe the temperature distribution of water velocity, as shown in Fig .4.

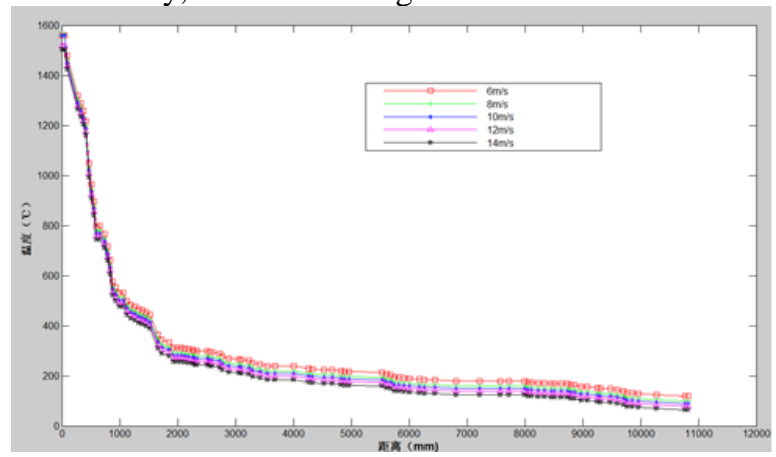

Figure 4. The temperature distribution curve in several different cooling water velocities

Take node of casting billet' s core to observe its stress distribution, still doing the above section and take 114 nodes from the beginning of crystallizer to the end of casting billet. The stress value of the selected node would be mapped curve to observe the stress distribution rule, and the core stress field of 5 different cooling water rates integration to the same coordinate system. Different linear represent different casting stress distribution curve of the core when the speed of cooling water is $6 \mathrm{~m} / \mathrm{s}, 8 \mathrm{~m} / \mathrm{s}, 10$ $\mathrm{m} / \mathrm{s}, 12 \mathrm{~m} / \mathrm{s}, 14 \mathrm{~m} / \mathrm{s}$. The results are shown in Fig .5.

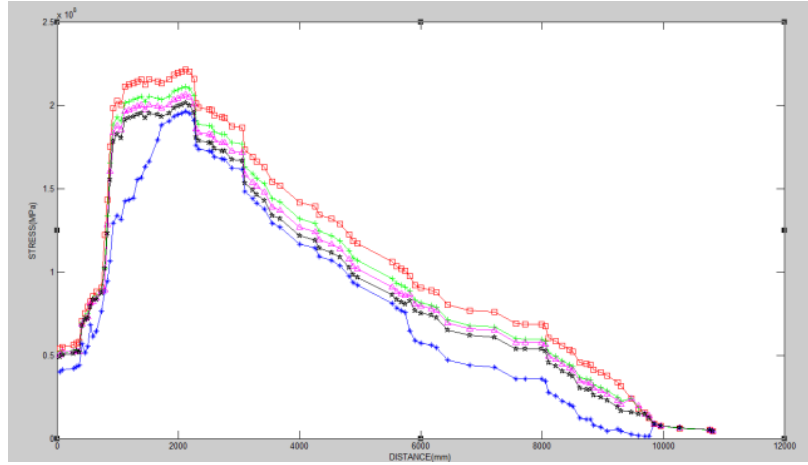

Figure 5. The stress curve of casting billet's core under 5 different cooling water rates

Can be seen from Fig .4, the stress curve of casting billet' $s$ core under 5 different cooling water rates is showed a trend of consistent. Stress is in the range of 0.5 meters increases rapidly, and the increased rate of stress is very big with the maximum value of $220 \mathrm{MPa}$. Then the stress is constantly falling with the increment of cooling speed, but the range of decrease become biggest when the cooling water rate is $10 \mathrm{~m} / \mathrm{s}$ with the maximum value of 50 $\mathrm{MPa}$. while continuing to increase speed of cold water to be $12 \mathrm{~m} / \mathrm{s}$ and $14 \mathrm{~m} / \mathrm{s}$, the degree of decrease is small, only $10 \mathrm{MPa}$ and $12 \mathrm{MPa}$. Slab stress of the core is the thermal stress, because the different temperature of material inside could produce different status and the existence of temperature difference influence every parts so that various parts' $s$ force is uneven, eventually thermal stress was produced. The effect of cooling water in the crystallizer was very severe, so that the outermost liquid steel was cooled rapidly while the core was still in the molten state and the temperature was very high which was characterized by large thermal stress. After leaving the crystallizer, temperature difference would become small and the corresponding stress would be reduced.

\section{CONCLUSIONS}

The finite element model of crystallizer and casting blank is established. The convective heat transfer coefficient of corresponding cooling water velocity is loaded under the outer part of crystallizer.On the outer surface of part of casting blank of crystallizer, The equivalent convection heat transfer coefficient is loaded according to the cooling effect of two district cooling bending arc, and other parts of the surface air cooler, loading comprehensive coefficient of convective heat transfer. According to relevant data, for the initial temperature of casting blank, the internal temperature of liquid steel is set to $1560{ }^{\circ} \mathrm{C}$ in the crystallizer, the temperature is decreased from up to down. Taking this as the boundary conditions and loads and making numerical simulation analysis of the model. The cooling water velocity of crystallizer is set as variables, respectively, as the $6 \mathrm{~m} / \mathrm{s}, 8 \mathrm{~m} / \mathrm{s}, 10 \mathrm{~m} / \mathrm{s}, 12 \mathrm{~m} / \mathrm{s}, 14 \mathrm{~m} / \mathrm{s}$, and then using the finite element method for stress analysis of the core of the casting blank. During the analysing, the decline of billet stress is the most obvious when the speed of cooling water ups to $10 \mathrm{~m} / \mathrm{s}$, downs to $50 \mathrm{Mpa}$, the stress in other water velocity also decreases but the effect is not obvious. So the cold water speed of $10 \mathrm{~m} / \mathrm{s}$ is optimal choice of crystallizer. 


\section{ACKNOWLEDGMENT}

This research reported in the paper was supported by Wuhan Polytechnic University Research Grant(Grant No.2014RZ37).This support is greatly acknowledged.

\section{REFERENCES}

[1] Singh, Ramnik ,Thomas, Brian G.,Vanka, Surya P. Large eddy simulations of double-ruler electromagnetic field effect on transient flow during continuous casting. Metallurgical and Materials Transactions B: Process Metallurgy and Materials Processing Science, 2014,45(3),1098-1115

[2] Okayasu, Mitsuhiro. Mechanical strength and failure characteristics of cast $\mathrm{Mg}-9 \% \mathrm{Al}-1 \% \mathrm{Zn}$ alloys produced by a heated-mold continuous casting process: Fatigue properties. Steel Research International, 2014,85(8), 1266-1273.

[3] Tiselj, Iztok . Double-sided cooling of heated slab: Conjugate heat transfer DNS. International Journal of Heat and Mass Transfer, 2013,66, 781-790.

[4] Zhan Meizhue. A Finite Element Analysis on Thermal Transformation and Thermal-Mechanical Deformation during $230 \mathrm{~mm} \times 1500 \mathrm{~mm}$ Slab Casting and Solidifying Process, SPECIAL STEEL, Vol. 2, 2014, pp. 5-8.
[5] CHE Xiao-mie, CHEN Wei-qing, ZHAO Jiang, Ma Fu-ping. Effects of SENs types on flow patterns and temperature distribution in bollom mold, Nonferrous Metals Science and Engineering, Vol. 3, 2012, pp. 32-36.

[6] Wang Zhangling, Dong Fang. Coupled numerical simulation and research for heat stress of continuous casting crystallizer, Journal of Inner Mongolia University of Science and Technology, 2012, 31 (3), 267-274

[7] Mao Bingliang, Ren Bingzhi, Han Zhiwei. Numerical simulation of heat transfer and solidification process of round bloom continuous casting, Industrial Heating, 2012, 41 (3), 50-53.

[8] Gao Peng, Liu Hongmin, Yu Bingqiang. Study on the scale of convective heat transfer coefficient in high pressure water plate, Journal of Yanshan University, 2014, 38 (3), 211-220.

[9] Zhang Xiaojun, Liu Xinhua, Wu Yongfu. The Copper clad aluminum billet horizontal continuous casting direct composite forming numerical simulation of temperature field, Foundry Engineering, 2013, 37 (3), 11-16.

[10] Jiang Yanbin, Liu Xiangai, Zhang Xiaojun. Cold type resistance angle on HCCM horizontal continuous casting of BFe10-1-1 pipe circumferential microstructure and mechanical properties of inhomogeneity, The Chinese Journal of Nonferrous Metals, 2014,24 (9), 2322-2332. 